\title{
Porteira Fechada sob a perspectiva da viagem
}

\section{Ana Paula Maggioni*}

Resumo: O presente trabalho objetiva ilustrar como ocorre o processo trânsito campo-cidade, caracterizando-se pela ruptura com a origem da personagem principal com sua estância, numa travessia a pé, rumo à cidade. Tal situação pode ser entendida como um mito do gaúcho a pé, representada muito bem na triologia de Cyro Martins. Porteira Fechada é a obra aqui apresentada sob essa análise, através dessa viagem.

Palavras-chave: viagem; campo; cidade; gaúcho.

\begin{abstract}
This paper intends to illustrate how the "countryside-city transit" process occurs, here represented by the rupture established by the main character with his background - his farm, while he treads towards the city. This situation may be understood as a myth of the "walking gaucho", very well depicted in Cyro Martins' trilogy. Porteira Fechada is the work presented here under this analysis, shown through that journey.
\end{abstract}

Keywords: journey; countryside; city; gaucho.

O presente trabalho objetiva estabelecer relações entre o processo de trânsito entre o campo e a cidade. A obra escolhida para tal é Porteira Fechada, de Cyro Martins, importante escritor gaúcho que, longe de ser menosprezado, deve ser valorizado por seu trabalho, principalmente por suas contribuições para o enriquecimento da literatura gaúcha. Porteira Fechada caracteriza-se por ser um romance social que enfoca a vida no campo, tratando da questão do êxodo para as cidades. Eis aí a presença da viagem nessa obra. É importante salientar que Porteira Fechada faz parte da triologia do gaúcho a pé, composta por Sem Rumo (1937), Porteira Fechada (1944) e Estrada Nova (1953). Para explicitar a criação desse mito, podemos nos valer das idéias de Solange Medina Ketzer, no capítulo As metáforas na triologia do gaúcho a pé, da obra organizada por Maria Helena Martins, Cyro Martins 90 anos:

Ao transportar o sentido de 'estar a pé' ao gaúcho, o ficcionista mexe com uma construção simbólica mítica desse homem que pressupõe o cavalo como extensão de sua valentia, coragem, bravura, altivez; como elemento inerente a sua própria identidade. (MARTINS, 1999, p.97)

Essa metáfora do cavalo fica muito evidente na passagem em que Guedes vende seu cavalo e, posteriormente, seus arreios, estando assim designado ao seu destino: andar a pé;

\footnotetext{
* Mestranda UFRGS
} 
como demonstrado nessa passagem em que ele se desfaz dos arreios: "Cortava assim o último tento que o prendia à vida passada. Curvava-se à fatalidade, cedendo a um desígnio doloroso de gaúcho a pé.”(MARTINS, 2001, p.113)

A viagem presente na obra Porteira Fechada, de Cyro Martins, aparece em vários momentos e de várias maneiras. A viagem psicológica também é representada nessa obra, embora bem menos notável. Um exemplo desse tipo de viagem é o excerto:

$\mathrm{Na}$ véspera de ser encontrado morto, João Guedes passara a tarde agachado à beira do rancho, testa franzida, profundamente nostálgico, mateando e rememorando coisas, enquanto as vistas se espichavam, num desejo de fuga, para a natureza vitimada pela seca. (MARTINS, 2001. p.114)

Este é um exemplo da chamada viagem interior, aqui João Guedes, ao lembrar do passado, volta no tempo e viaja, desejando fugir do local onde se encontra, por insatisfação pessoal. Além disso, as constantes lembranças do passado que a personagem faz são consideradas viagens psicológicas, vistas, na obra em questão, como uma espécie de remorso pelo que deixou de fazer ou que perdeu.

Mas a viagem geográfica é a que mais aparece na obra em questão, através de João Guedes, o estancieiro que é despejado por seu patrão. A partir desse fato é desencadeada sua viagem, pois, ao saber da notícia de que precisaria se retirar, ele pensa:

Nunca fora desses que gostam de andar com a tarecama de um lado para o outro. Mesmo quando solteiro, sempre fez questão de ser peão parador. E agora, ter que se botar na estrada, de repente, naquela altura da vida! Que rumo tomar? (MARTINS, 2001, p.27)

Nesse momento da narrativa há a quebra da situação inicial e surge o problema: sair de onde se está. Como se pode constatar, a personagem não gostava de ter que viajar, preferia a comodidade, o lugar estanque e, ter que partir, era uma terrível notícia. Essa característica está presente na triologia de Cyro Martins e é explicada na obra Cyro Martins 90 anos, organizada por Maria Helena Martins:

... os protagonistas de Sem Rumo, Porteira Fechada e Estrada Nova, constituem personagens representativas de diferentes dramas vividos por habitantes do campo. Todos têm suas trajetórias marcadas pela necessidade de abandonar a terra, mesmo que a contragosto. (MARTINS, 1999, p 98)

Esse abandono, tão temido pelo estancieiro, pode ser explicado pelo fato de que toda pessoa que se desloca no espaço muda enquanto pessoa, pois não é possível mudar de lugar e não mudar traços da personalidade. Ele não estava preparado para essa mudança em sua vida, até porque achava que não tinha mais idade para isso. Além disso, o encontro com o desconhecido pode gerar conflitos, como os que teme João Guedes e que é explicado por Wladimir Krysinski, em sua obra Discurso de viagem e senso de alteridade: 
Aos olhos do narrador-poeta, mas também na consciência refletora da etnografia, os universos étnicos e psicológicos conservam sempre uma parte do hermetismo: jamais poderemos conhecê-los completamente. A alteridade é fundamentalmente desconhecida. [...] O outro é tão outro que jamais poderei conhecer. (KRYSINSKI, 2003, p. 24- 25)

O Outro, para o estancieiro, causa medo, justamente por se saber que nunca há como conhecê-lo por completo, diferente do que Guedes vivia na campanha, onde, por estar situado há tanto tempo, sentia-se à vontade e seguro. Essa insegurança é tanta que ele vai adiando sua saída da campanha, tentando evitar a ida para a cidade.

A trajetória dele e de sua família é marcada pela pobreza e pela ignorância diante do novo, o que fica bem evidente nos fatos que mostram um pouco da mudança da família, que iria pedir ajuda à família de uma prima de Maria José, esposa de Guedes: "No dia da mudança, Maria José viajou empoleirada com as filhas no carrinho de quatro rodas do finado Bento [...] Alimentava uma secreta curiosidade, que a ida para a cidade avivara intensamente [...]" (MARTINS, 2001, p.54)

Apesar de contrariada, Maria José tinha vontade de rever sua prima da cidade e, de certa forma, comparar essa consigo mesmo, analisando a diferença de cada uma, principalmente por uma ter escolhido a campanha para viver e a outra a cidade. Vê-se ainda que, o transporte usado para a mudança foi um carrinho de quatro rodas, que facilitou o transporte da família e que é citado por Maria Alzira Seixo, na sua obra já mencionada anteriormente: “... o meio de transporte representa a possibilidade, para o homem, de uma locomoção rápida (que designa o esforço de compensação, o anseio de ganhar espaço perdendo menos tempo),...” (SEIXO, 1998, p.20)

O transporte significava para Maria José e suas filhas um facilitador, mas, apesar disso, Guedes não tinha pressa em chegar ao seu destino.

Durante o caminho, o diálogo das filhas com Maria José mostra o quanto essas estavam curiosas, só que positivamente, pois iriam conhecer a cidade, ter a possibilidade de uma vida melhor, eram jovens e não havia mal nenhum em se aventurar, ao contrário do pai:

- A nossa casa fica no centro mamãe? 'Que sabem vocês de centro!' - refletia a mãe [...]

- E quando é que nóis bamo conhecê cinema? [...] - E a gente vai passeá na praça, mamãe?" (MARTINS, 2001, p.54-55)

As filhas tinham curiosidade diante do Outro e, mais do que isso, para elas, a mudança era sinal de prosperidade, de abandono da ignorância para entrar no mundo civilizado. Essa expectativa é própria da viagem, conforme explica Maria Alzira Seixo, em sua obra Poéticas da Viagem na Literatura: "Toda a viagem se fundamenta numa expectativa, e, por isso ela é sempre corrente. Expectativa comercial, de conquista, de conhecimento, de mudança, de prazer, de expectativa incógnita muitas vezes...” (SEIXO, 1998, p.30-31) 
É importante notar ainda que, toda viagem é movimento, onde há paragens, ou seja, uma pausa onde há uma passagem (travessia) para encontrar o outro. Essa idéia de movimento é muito bem exemplificada pelo termo deslocação, conforme explica Seixo:

A matriz tipológica da viagem escrita, quer na literatura de viagens, quer na literatura das viagens, centra-se na deslocação (um lugar é substituído por outro lugar mediante um percurso determinado) [...] $\mathrm{O}$ acentuar da paragem na deslocação (ligando a viagem muito mais a um ritmo do que a um impulso, sobretudo quando se trata de várias paragens, e por isso tornando-a consentânea da existência humana e decalcando-a na respiração do quotidiano) [...]

(SEIXO, 1998, p.22)

O ritmo que marca a viagem de Guedes dá-se por um movimento de deslocação mais rápido, onde não há presença de paragens no momento de sua mudança, sendo essa bastante rápida. Entre algumas das idéias de paragem que aparecem na narrativa, podemos citar essa, em que João Guedes usa seu cavalo para se locomover: “[...] João Guedes botou os arreios no cavalo, montou e saiu sorumbático para o campo, de ânimo caído e ouvidos cheios. Ao tranco, as rédeas frouxas, deixando livre o animal para que o levasse aonde quisesse, [...]" (MARTINS, 2001, p.29)

Nessa passagem nota-se que não há preocupação com a velocidade, pois Guedes andava sem rumo. No entanto, há relação entre ele e seu meio de locomoção, para situá-los no espaço em que se inserem, o que é explicado também por Seixo:

Porque não é a velocidade que marca a situação de viagem [...], mas sim a conjunção entre um corpo (sujeito) que se move e o meio (de transporte) que o faz mover, em simultânea disjunção com o seu espaço que essa movência implica, provocando um desfasamento (processo de viagem - que implica sempre a questão: onde se está agora?E a seguir?) que reintegra o sujeito, ao fim de algum tempo (=espaço), num outro espaço. (SEIXO, 1998, p.29)

A conjunção entre sujeito e meio não se dá no caso de Guedes, pois esse simplesmente se deixa levar, como que renunciando ao seu papel de guia, deixando ao animal, sinônimo de sua proteção, essa escolha.

De sua tomada de decisão para partir até sua chegada na cidade, passa-se facilmente, porém, é na cidade que se encontra o grande problema na vida de Guedes e sua família, pois essa viagem lhe causa degradação. O próprio Guedes tinha consciência dessa degradação e datava-a do dia em que roubou uma ovelha pela primeira vez, perdendo sua dignidade. $\mathrm{O}$ roubo de ovelhas torna-se comum na vida do antigo estancieiro, que queria sustentar sua família, porém, num desses delitos ele é preso. Após alguns meses ele é libertado e, ao sair da prisão, já não é mais o mesmo homem, como comprova o trecho abaixo:

João Guedes, barbudo, desajeitado, com umas bombachas estreitas semeadas de remendos, um casaco de brim justo e umas alpargatas furadas, deixou-se conduzir passivamente pela mulher, as filhas e o filho. Não demonstrou maior alegria ao se ver livre. Na realidade, oprimia-o uma sensação de angústia, de vítima que se vê arrastada duma prisão para outra, talvez pior. (MARTINS, 2001, p.107) 
O fato de João deixar-se conduzir demonstra sua insatisfação, diferente do que ocorre quando há uma expectativa em relação a uma viagem que irá realizar-se. Aqui consolida-se sua total desilusão diante do outro e o principal fator desencadeador disso tudo é a obrigatoriedade com que Guedes precisava cumprir seu caminho. Desde o começo de sua trajetória ele foi forçado, nunca havendo empolgação diante da partida. Esse movimento de ser "jogado" para uma viagem involuntária é muito bem explicado por Décio Freitas, na introdução da obra "Porteira Fechada":

E João Guedes é expulso do seu pedaço de terra, atirado sem rumo na estrada, indo para os ranchos que cercam Boa Ventura, uma típica cidadezinha do interior. Ali ele vai sofrer um processo implacável de decadência material e moral que culmina com a prática do roubo, a morte por tuberculose duma das filhas, a perdição moral" (MARTINS, 2001, p.11)

Como vemos, a decadência de Guedes se dá justamente quando ele é obrigado a partir para Boa Ventura, o irônico nome do lugarejo, que opõe-se ao que vive a família dele ali. Há aqui uma forte relação com o homem e seu lugar de origem ou lugar a que se adaptou, sendo a viagem uma armadilha perigosa. Sua insatisfação era tanta que, ao voltar para a casa após a prisão, não ficou feliz, pelo contrário, sentiu-se até pior, já que estava indiferente à vida, a tudo que lhe cercava. A única diferença notável era a sensação que tinha ao ouvir da mulher as novidades a respeito dos vizinhos: "Era como se houvesse chegado de viagem. Mas não havia nada de novo. Tudo velho na aldeia. A mesmice choca de sempre" (MARTINS, 2001, p.108)

Parece que João chegou de viagem porque a esposa ficara lhe contando coisas que tinham acontecido na vizinhança, o que não era comum quando ele estava em liberdade e também não era comum que ele e a mulher dialogassem por tanto tempo. Todas essas atitudes pessimistas diante dos fatos revelam o quanto era deplorável sua condição. Tal condição é relacionada a saída do campo, ambiente próprio ao gaúcho, para a vida urbana, que Antonio Hohlfeldt vê como uma fatalidade, em sua obra $O$ Gaúcho: Ficção e realidade: "O fatalismo que marca a concepção de vida do gaúcho ganha em João Guedes, absolutamente desenraizado, uma colocação de auto-abandono e autocomiseração." (HOHLFELDT, 1982, p.77)

A situação em que o estancieiro se encontrava era desanimadora, pois tinha atingido a marginalização de sua pessoa, fator esse que resultava de sua vinda para a cidade, ainda mais sendo forçado a o fazer. É o que Antonio Hohlfeldt explica em sua obra citada anteriormente, referindo-se às personagens João Guedes e Janguta: “....ambos são empurrados, cada vez mais, para longe do campo, sempre mais perto da marginalização citadina a que a especialização das pastagens os força." (HOHLFELDT, 1982, p.78) 
Essa situação de "empurramento" como fator desencadeante da viagem aparece na literatura normalmente como um fator negativo, que corrompe o viajante, já que é comum a pessoa mudar ao fazer uma viagem. O mesmo caso ocorre em Vidas Secas, de Graciliano Ramos, onde Fabiano é encurralado pelo destino, que faz com que ele tenha que partir para a família não morrer durante a seca nordestina. Seu caminho é marcado pela desventura, inclusive com sua prisão injusta, assemelhando-se assim muito à obra de Cyro Martins, que, provavelmente baseou-se na personagem de Graciliano Ramos para moldar João Guedes, contextualizando a personagem ao pampa gaúcho, pois faz uso também desse recurso de caminho de desventura.

É importante nesse momento salientar a situação histórica do Rio Grande do Sul, que vivia profundas e marcantes modificações sócio-econômicas no Estado no período que é enfocado por Cyro Martins, o que marcou pela introdução do gaúcho a pé na gauchesca riograndense. Esse movimento "para fora" abriu possibilidades para que se pensasse o peão como desertor e, mais marcante ainda, o retirante a pé, sem rumo e sem perspectiva de melhora. Antonio Hohlfeldt explica isso muito bem na obra já mencionada: “...não mais o peão, apenas, está marginalizado, mas a transformação das pastagens, a modificação econômica da província, a expansão das pastagens, faz com que também os pequenos e médios estancieiros sofram uma marginalização.” (HOHLFELDT, 1982, p.73)

O desfecho da personagem João Guedes é marcado pela sua trajetória, é como se desde que ele saiu da estância tivesse iniciado seu processo de morte, pois aos poucos foi esmorecendo, até chegar ao seu fim. A narrativa inicia relatando a morte dele, cujo corpo foi encontrado na beira de uma sanga e a partir daí traçam-se os últimos caminhos da personagem, cuja morte já se prenunciara no momento em que ele precisou deixar a fazenda. Se considerarmos as condições de sua morte, podemos perceber o quanto foi trágico o seu destino:

\footnotetext{
João Guedes, um dos assíduos freqüentadores do boliche do capitão, mudara-se da campanha havia três anos. Três anos de pobreza na cidade bastaram para o degradar. Ao morrer, não tinha vintém nos bolsos e fazia dois meses que saíra da cadeia, onde estivera preso por roubo de ovelha. (MARTINS, 2001, p.20)
}

A sua morte foi sua libertação e o fim de um legado de miséria e vergonha. No dia de seu sepultamento aparece finalmente uma imagem serena, diferente daquelas visões de Boa Ventura que Guedes possuía. O que chama a atenção nessa imagem agradável é o remetimento da cena ao campo, mostrando que só lá era possível observar-se semelhante imagem. A terra é vista como símbolo de prosperidade, onde a paz, perdida por Guedes desde sua partida, reina absoluta: 
Longe de Boa Ventura, lá no fundo duma estância, numa invernada de dez quadras de sesmaria, lotada de bois, defrontavam-se três taperas: a do Bentinho, a do João Guedes e a da Gertrudes. Sobravam algumas árvores, algumas pedras e os sinais de moradia humana no chão. Nada mais. Os bois gostavam de lamber aquela terra. (MARTINS, 2001, p.151)

A imagem da campanha aqui é nostálgica e dá a entender que Guedes estando sob a terra podia encontrar-se feliz, sendo agora parte dessa e não mais sofrendo a desventura de ter se perdido na cidade. A paz em que ele vivia foi quebrada pela viagem para fora dos pampas, mas que após sua morte é reencontrada, expressa claramente na frase que encerra a obra: Que paz naqueles campos!

Não há dúvidas de que Cyro Martins idealizou o campo e reprimiu o movimento migratório involuntário para a cidade, porém, sua narrativa assumiu cunho histórico por relatar o drama dos peões que precisavam abandonar as estâncias. Sua obra pode não atingir proporções exorbitantes em relação à literatura gaúcha, mas com certeza possui notoriedade e deve ser respeitada pelo seu caráter regionalista e histórico. Dotado de uma linguagem simples, o autor consegue montar muito bem a figura do homem do campo e sua não adaptação à cidade, enfatizando as raízes gauchescas de nosso povo, além de traçar muito bem a viagem que esses homens precisavam fazer para tentar buscar a prosperidade.

\section{Referências}

HOHLFELDT, Antonio. Ficção e Realidade. RJ, Edições Antares; Brasília: INL, 1982.

KRYSINSKI, Wladimir. Discurso de viagem e senso de alteridade. Porto Alegre, Revista Organon. Instituto de Letras/UFRGS, volume 17.

MARTINS, Cyro. Porteira Fechada. Movimento, Porto Alegre, 2001.

MARTINS, Maria Helena (org.). Cyro Martins 90 anos. Porto Alegre: CELPCyro Martins:IEL:CORAG, 1999.

MASINA, Léa, APPEL, Myrna Bier (orgs.). A Geração de 30 no Rio Grande do Sul: literatura e artes plásticas. Porto Alegre, Ed. Universidade/UFRGS, 2000.

SEIXO, Maria Alzira. Poéticas da viagem na literatura. Lisboa: Cosmos, 1998. 